\title{
PENGARUH PROFESIONALISME AUDITOR, ETIKA PROFESI DAN \\ PENGALAMAN AUDITOR TERHADAP PERTIMBANGAN TINGKAT \\ MATERIALITAS DENGAN KREDIBILITAS KLIEN SEBAGAI PEMODERASI
}

\author{
Galeh Utami \\ Alumni Prodi Akuntansi Universitas Negeri Yogyakarta \\ galeh.candrakirana@gmail.com \\ Mahendra Adhi Nugroho \\ Jurusan Pendidikan Akuntansi Universitas Negeri Yogyakarta
}

\begin{abstract}
Abstrak: Pengaruh Profesionalisma Auditor, Etika Profesi, dan Pengalaman Auditor terhadap Pertimbangan Tingkat Materialitas dengan Kredibilitas Klien sebagai Pemoderasi. Tujuan dari penelitian ini adalah untuk memberikan bukti empiris mengenai pengaruh profesionalisme auditor, etika profesi dan pengalaman auditor pada pertimbangan tingkat materialitas. Selain itu, juga memberikan bukti empiris mengenai efek moderasi dari kredibilitas klien dalam pengaruh ketiga variabel independen pada pertimbangan tingkat materialitas. Populasi dalam penelitian ini adalah auditor yang bekerja di Kantor Akuntan Publik wilayah Daerah Istimewa Yogyakarta. Sampel dalam penelitian ini adalah seluruh auditor yang bekerja pada Kantor Akuntan Publik tersebut. Jenis penelitian ini adalah penelitian deskriptif dan explanatory research. Teknik yang digunakan dalam penelitian ini adalah analisis jalur dengan partical least square. Hasil penelitian ini menunjukkan bahwa: (1) Profesionalisme auditor berpengaruh signifikan dan negatif pada pertimbangan tingkat materialitas, yang ditunjukkan oleh nilai t-ststistik $\geq 1,96$, yakni sebesar 4,112, dengan koefisiennya menunjukkan angka -0,419. (2) Tidak terdapat pengaruh signifikan etika profesi pada pertimbangan tingkat materialitas, yang ditunjukkan dengan nilai t-statistik <1,96 yakni 1,691, sedangkan koefisiennya menunjukkan angka 0,231. (3) Pengalaman auditor tidak berpengaruh pada pertimbangan tingkat materialitas, yang ditunjukkan dengan nilai t-statistik $<1,96$ yakni 1,727, sedangkan koefisiennya menunjukkan angka 0,119. (4) Krediblitas klien secara signifikan memoderasi pengaruh antara profesionalisme auditor pada pertimbangan tingkat materialitas yang ditunjukkan dengan nilai t-statistik $\geq 1,96$ yakni 4,209, sedangkan koefisiennya menunjukkan angka 0,415. (5) Kredibilitas klien secara signifikan memoderasi pengaruh etika profesi terhadap pertimbangan tingkat materialitas, yang ditunjukkan dengan nilai t-statistik $\geq 1,96$ yakni 2,456 , sedangkan koefisiennya menunjukkan angka $-0,314$. (6) Kredibilitas klien tidak memoderasi pengaruh pengalaman auditor terhadap pertimbangan tingkat materialitas, yang ditunjukkan oleh nilai t-statistik $<1,96$ yakni 1,580 , sedangkan koefisiennya menunjukkan angka 0,121 .
\end{abstract}

Kata kunci: Profesionalisme, Etika Profesi, Pengalaman, Pertimbangan Tingkat Materialitas, Kredibilitas Klien.

Abstract: The Influence of Profesionalism, Professional Ethics, and Auditor Experience to Materiality Judgment with Client Credibility as Moderating Variable. The aim of this research is to find empirical proof about the influence of auditor profesionalism, professional ethics, and auditor experience to materiality judgement. Another aim is to give empirical proof about the influence of client credibility as moderating variable in the influence of those 
three independent variables to materiality judgement. The population of the research is auditor who works in public accounting firm in Daerah Istimewa Yogyakarta. Sample of research is all auditors who work in that public accounting firm. This research belong to deskriptive research and explanatory research. The analysis metod of this research use path analysis with partial leas square. The results show that: (1) profesionalism has significant influence and negative in materiality judgement. It is showed by value of $t$-Statistic (4112) $\geq$ 1,96, its path coefficient is -0,419. (2) Professional ethics has no significant influence to materiality judgement. It is showed by value of statistic $(1,691) \leq 1,96$, its coefficient is 0,231 . (3) auditor experience has no significant to materiality judgement it is showed by value of $t$ statistic $(1,727)<1,96$, its coefficient is $-0,119$. (4) client credibility as moderating variable can moderate significantly in the influence of auditor profesionalism to materiality judgement it is showed by value t-statistic $(4,209) \geq 1,96$, its coefficient is 0,415. (5) client credibility as moderating variable can moderate significantly in the influence of professional ethics to materiality judgement it is showed by value $t$-statistic $(2,456) \geq 1,96$, its coefficient is $-0,314$. (6) client credibility as moderating variable can't moderate in the influence of auditor experience to materiality judgement it is showed by value $t$-statistic $(1,580)<1,96$, its coefficient is 0,121 .

Keywords: Profesionalism, Professional Ethics, Experience, Materiality Judgement, Client Credibility.

\section{PENDAHULUAN}

Pertimbangan materialitas merupakan pertimbangan profesional yang dipengaruhi persepsi auditor atas kebutuhan orang yang memiliki pengetahuan memadahi dan yang meletakkan kepercayaan pada laporan keuangan (SPAP 2001, SA Seksi 312: 10). Pertimbangan tingkat materialitas sangat penting dalam pengambilan keputusan, hal ini berkaitan dengan hasil akhir audit yang akan digunakan oleh pemakai informasi, sehingga harus di laksanakan dengan penuh hati-hati dan kecermatan.

Berkenaan dengan lingkup pengujian, penentuan ukuran sampel dan item yang akan diuji, pertimbangan (judgment) auditor akan sangat mempengaruhi, dalam hal ini mencakup materialitas, risiko, biaya, manfaat, ukuran, dan karakteristik populasi. Banyak faktor yang dapat mempengaruhi pertimbangan tingkat materialitas diantaranya adalah profesionalisme auditor.

Munculnya pandangan skeptis terhadap profesi akuntan publik memang beralasan karena cukup banyak laporan keuangan suatu perusahaan yang mendapatkan opini wajar tanpa pengecualian, tetapi justru mengalami kebangkrutan setelah opini tersebut dikeluarkan. Hal tersebut membuat masyarakat meragukan independensi dan kredibilitas auditor sebagai seorang profesional.

Berkaitan dengan pertimbangan tingkat materialitas, etika profesi sangat berpengaruh, karena semua berawal dari masing-masing individu dalam bersikap 


\section{JURNAL NOMINAL / VOLUME III NOMOR 1 / TAHUN 2014}

sesuai etika profesinya. Selain etika profesi, akuntan juga dituntut kemampuannya terkait pengetahuan atau pengalamannya dalam melakukan audit sehingga pertimbangan tingkat materialitas dalam proses audit laporan keuangan diberikan sewajarnya sesuai dengan kondisi sebenarnya.

Haynes (1998) dalam Susetyo (2009) mengemukakan bahwa banyak faktor yang dapat mempengaruhi pertimbangan auditor khususnya dalam mengevaluasi bukti audit, diantaranya adalah preferensi klien dan pengalaman audit. Akuntan yang lebih berpengalaman akan bertambah pengetahuannya dalam melakukan proses audit khususnya dalam memberikan pertimbangan tingkat materialitas dalam proses audit laporan keuangan.

Biasanya hasil tertentu yang diinginkan oleh klien yang diaudit adalah untuk mendapatkan unqualified opinion sehingga kinerja dari perusahaannya dapat dikatakan baik dan bagi perusahaan yang go public dapat meningkatkan nilai sahamnya di pasar modal. Untuk mencapai tujuan tersebut, klien tidak jarang menyatakan keinginan atas suatu hasil tertentu atau perlakuan akuntansi tertentu agar laporan keuangan terlihat baik. Ada juga klien yang berusaha mempengaruhi auditor agar mau menuruti keinginannya dengan membayar sejumlah uang.

Jenkins dan Heynes (2003) menerangkan bahwa pengaruh dari preferensi klien yang berupa waktu penyampaian dan kredibilitas klien terhadap pertimbangan tingkat materialitas menunjukkan bahwa waktu penyampaian akan berpengaruh terhadap pertimbangan tingkat materialitas dalam tugas pengungkapan, bukan dalam tugas pengukuran, sedangkan kredibilitas klien akan mempengaruhi pertimbangan tingkat materialitas dalam kondisi preferensi awal.

Berdasarkan beberapa faktor yang mungkin dapat mempengaruhi pertimbangan tingkat materialitas, penelitian ini akan lebih fokus untuk meneliti tentang profesionalisme auditor, etika profesi dan pengalaman auditor. profesionalisme dipilih karena berkaitan dengan tanggung jawab seorang auditor dalam melaksanakan tugasnya, sikap profesionalisme yang tinggi akan menunjukkan kinerja yang bagus, dalam hal ini adalah dalam melakukan pertimbangan materialitas.

Berperilaku etis sesuai dengan etika profesi yang dianut menunjukkan bahwa seorang auditor tersebut dapat berkomitmen dengan baik dalam menjalankan tugasnya. Perilaku etis merupakan hal yang paling mendasar dalam melakukan suatu pekerjaan. Segala sesuatu yang berawal dari kesadaran dan ketulusan dalam bekerja maka hasilnya juga akan lebih baik.

Pengalaman auditor juga sangat penting terkait dengan pertimbangan tingkat materialitas, karena pengalaman ini 
berkaitan dengan keahlian dan pengetahuan seorang auditor dalam menangani suatu kasus.

auditor bekerja untuk memeriksa kewajaran dari entitas klien, baik itu entitas bisnis, organisasi maupun lainnya, dan semuanya berkaitan dengan klien. Selain bukti-bukti yang relevan, dalam proses audit juga membutuhkan informasi-informasi yang dapat membantu jalannya pemeriksaan. Preferensi-preferensi dari klien inilah yang nantinya akan menjadi bahan pertimbangan auditor namun, hal tersebut tidak terlepas dari tingkat keakuratan informasi yang disampaikan, jadi baik secara langsung maupun tidak langsung kredibilitas klien akan mempengaruhi auditor dalam mempertimbangkan tingkat materialitas.

\section{METODE PENELITIAN}

\section{Jenis Penelitian}

Penelitian ini merupakan Descriptive dan Explanatory Research. Penelitian deskriptif merupakan penelitian yang bertujuan menggambarkan suatu peristiwa, siapa yang terlibat, apa yang dilakukan, kapan dilakukan, kapan dilakukan, di mana, dan bagaimana melakukannya. Penelitian eksplanatori merupakan penelitian yang mencoba menjelaskan fenomena yang ada.

\section{Target/Subjek Penelitian}

Subjek dari penelitian ini adalah Auditor yang Bekerja di KAP wilayah DIY. Sampelnya adalah seluruh aduitor yang bekerja pada KAP tersebut.

\section{Data, Instrumen, dan Teknik Pengumpulan}

Jenis data yang digunakan dalam penelitian ini adalah data kuantitatif yaitu Data primer yang diperoleh dari jawaban auditor dengan menggunakan kuesioner.

Populasi dalam penelitian ini adalah auditor dan sampel dalam penelitian ini adalah seluruh auditor yang bekerja di KAP wilayah DIY.

\section{Teknik Analisis Data}

Analisis deskriptif berisi mengenai bahasan secara deskriptif terkait tanggapan yang diberikan oleh responden terhadap kuesioner.

Pengukuran validitas dalam penelitian ini dilakukan dengan 2 (dua) tahapan, yakni validitas diskriminan dan konvergen. Uji validitas secara diskriminan maupun konvergen dilakukan dengan menggunakan program Partial Least Square. Partial Least Square (PLS) merupakan gabungan dari analisis regresi analisis jalur dengan analisis faktor (konfirmatori) dan atau analisis komponen utama (Solimun, 2010:160).

Uji validitas diskriminan dilakukan dengan melihat nilai cross loading setiap 
indikator dari masing-masing variabel. Setiap indikator pengukur variabel dinilai memenuhi validitas diskriminan apabila nilai cross loading setiap indikator dari variabel yang bersangkutan lebih besar dibandingkan dengan cross loading variabel lain (Solimun, 2010).

Uji reliabilitas instrumen dalam penelitian ini dilakukan dengan composite reliability. Nilai composite reliability dari setiap variabel minimal 0,70 maka variabel yang diuji telah memenuhi syarat reliabilitas (Solimun,2010).

Uji goodness of fit inner model dalam penelitian dapat dilihat dari nilai R-square untuk masing-masing variabel endogen pada persamaan struktural. Selain itu, pemeriksaan goodness of fit inner model juga dapat dilihat dari nilai $\mathrm{Q}^{2}$ predictive relevance. Besarnya nilai $\mathrm{Q}^{2}=1-\left(1-\mathrm{R}^{2}\right)$ $\left(1-\mathrm{R}_{2}^{2}\right) \ldots .\left(1-\mathrm{R}_{\mathrm{p}}^{2}\right)$.

Dalam rangka mengidentifikasi tingkat kepentingan dari setiap indikator dalam mengestimasi variabel laten, dapat dilakukan dengan melihat nilai outer loading setiap indikator dalam mengestimasi masing-masing variabel. Sedangkan nilai yang menunjukkan kondisi aktual setiap indikator menurut persepsi responden dilihat dari nilai mean dari setiap indikator.

Uji hipotesis dalam penelitian ini dilakukan dengan menggunakan teknik analisis jalur dengan partial least square untuk menentukan dalam menolak atau menerima hipotesis yang diajukan. Analisis jalur dilakukan dengan metode resampling Bootstrap yang dikembangkan oleh Geisser dan Stone. Pengujian dilakukan dengan ttest, hipotesis yang diajukan diterima apabila memiliki nilai t-statistik $\geq 1,96$.

\section{HASIL PENELITIAN DAN PEMBAHASAN}

Uji hipotesis dalam penelitian ini dilakukan dengan menggunakan teknik analisis jalur dengan partial least square untuk menentukan dalam menolak atau menerima hipotesis yang diajukan.

Tabel 1. Koefisien Uji Hipotesis

\begin{tabular}{|l|c|c|c|c||}
\hline \multicolumn{1}{|c|}{ Pengaruh } & $\begin{array}{c}\text { Koefisien } \\
\text { Jalur }\end{array}$ & T-Statistik & Signifikansi & Keterangan \\
\hline \hline $\begin{array}{l}\text { Profesional Auditor } \rightarrow \\
\text { Pertimbangan Tingkat } \\
\text { Materialitas }\end{array}$ & $-0,419$ & 4,112 & Signifikan & Tidak Mendukung $\mathrm{H}_{1}$ \\
\hline $\begin{array}{l}\text { Etika Profesi } \rightarrow \text { Pertimbangan } \\
\text { Tingkat Materialitas }\end{array}$ & 0,231 & 1,691 & $\begin{array}{c}\text { Tidak } \\
\text { Signifikan }\end{array}$ & Tidak Mendukung $\mathrm{H}_{2}$ \\
\hline $\begin{array}{l}\text { Pengalaman } \rightarrow \text { Pertimbangan } \\
\text { Tingkat Materialitas }\end{array}$ & $-0,119$ & 1,727 & $\begin{array}{c}\text { Tidak } \\
\text { Signifikan }\end{array}$ & Tidak Mendukung $\mathrm{H}_{3}$ \\
\hline $\begin{array}{l}\text { Kredibilitas Klien * Profesional } \\
\text { Auditor } \rightarrow \text { Pertimbangan } \\
\text { Tingkat Materialitas }\end{array}$ & 0,415 & 4,209 & Signifikan & Mendukung $\mathrm{H}_{4}$ \\
\hline $\begin{array}{l}\text { Kredibilitas Klien * Etika } \\
\text { Profesi } \rightarrow \text { Pertimbangan Tingkat } \\
\text { Materialitas }\end{array}$ & $-0,314$ & 2,456 & Signifikan & Mendukung $\mathrm{H}_{5}$ \\
\hline $\begin{array}{l}\text { Kredibilitas Klien * } \\
\text { Pengalaman } \rightarrow \text { Pertimbangan } \\
\text { Tingkat Materialitas }\end{array}$ & 0,121 & 1,58 & $\begin{array}{c}\text { Tidak } \\
\text { Signifikan }\end{array}$ & Tidak Mendukung $\mathrm{H}_{6}$ \\
\hline
\end{tabular}

Sumber: Data Primer Diolah, 2014. 


\section{JURNAL NOMINAL / VOLUME III NOMOR 1 / TAHUN 2014}

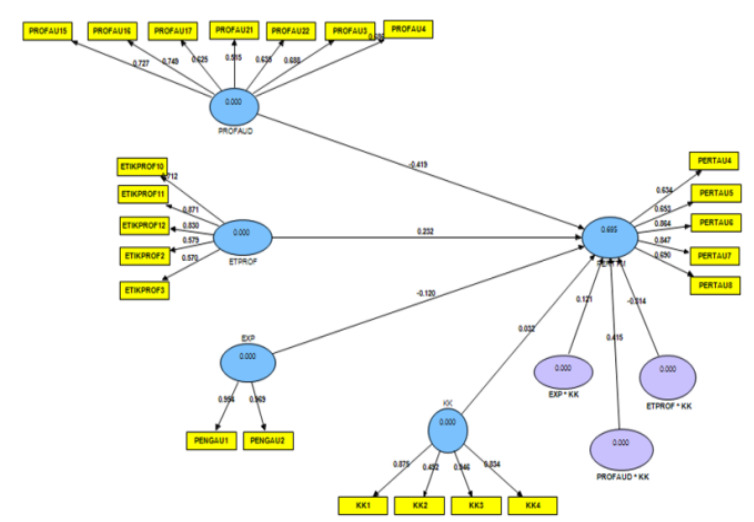

Gambar 1. Hasil Uji Statistik dengan

Analisis Jalur, Sumber Data : Hasil Olah

Data dengan PLS V2 M3

Profesional auditor memiliki pengaruh yang signifikan pada pertimbangan tingkat materialitas. Hasil analisis menggunakan PLS diperoleh koefisien jalur sebesar -0,419 dengan nilai t-statistik $\geq 1,96$ yakni sebesar 4,112. Hal ini menunjukkan terdapat pengaruh antara profesional auditor dan pertimbangan tingkat materialitas dan pengaruhnya bersifat negatif.

Hasil negatif secara statistik, bukan berarti menggugurkan konsep yang sudah mapan yakni profesionalisme berpengaruh positif pada pertimbangan tingkat materialitas, namun terdapat kondisi khusus dalam konteks penelitian serta sangat dipengaruhi oleh instrumen yang digunakan dalam menggali mengenai pertimbangan tingkat materialitas. Dalam konteks auditor pada Kantor Akuntan Publik di wilayah Yogyakarta, semakin tinggi tingkat profesionalisme seorang auditor, maka akan semakin tidak mudah dalam memberikan keputusan-keputusan dalam rangka memenuhi harapan/keinginan klien.

Hal ini berarti, semakin tinggi tingkat profesionalisme yang dimiliki seorang auditor, maka pertimbangan dalam memutuskan pemenuhan keinginankeinginan klien akan semakin ketat. Seorang auditor yang profesional tidak akan terlalu mudah dan murah dalam mengambil keputusan dalam rangka memenuhi keinginan klien. Kondisi inilah yang menjadikan hubungan antara profesionalisme auditor dan pertimbangan tingkat materialitas berbanding terbalik atau hubungan yang negatif.

Etika profesi tidak berhubungan dengan pertimbangan tingkat materialitas. Hasil analisis menggunakan PLS menunjukkan nilai t-statistik <1,96 yakni sebesar 1,691 sedangkan nilai koefisien jalurnya sebesar 0,231. Dengan demikian etika profesi tidak mempengaruhi pertimbangan tingkat materialitas, karena etika profesi lebih cenderung ke arah perilaku seorang auditor dalam menjalankan tugasnya, bukan terhadap pertimbangan tingkat materialitas.

Pengalaman tidak berpengaruh signifikan pertimbangan tingkat materialitas. Hal tersebut ditunjukkan oleh nilai t-statistik $<1,96$ yakni 1, 727 dengan koefisien jalur menunjukkan angka -0,119. Pengalaman auditor dalam memberikan suatu pertimbangan tentang materialitas 


\section{JURNAL NOMINAL / VOLUME III NOMOR 1 / TAHUN 2014}

tidak berpengaruh karena responden dalam penelitian ini sebagian besar adalah junior dan senior, yang ditunjukkan dengan persentase sebesar $70 \%$ dari responden yang menduduki jabatan sebagai junior dan sisanya sebesar $30 \%$ menduduki jabatan sebagai senior, sedangkan yang memberikan suatu pertimbangan adalah auditor yang memiliki jabatan sebagai supervisor, manajer dan partner. Alasan lain pengalaman auditor tidak berpengaruh pada pertimbangan tingkat materialitas karena dalam konteks auditor di DIY jumlah kasus yang ditangani tidak mencerminkan pengalaman auditor, hal ini dimungkinkan bahwa jumlah penugasan yang di pegang oleh auditor hanya secara kuantitas saja dan bukan secara kualitas, karena peneliti tidak meneliti tentang kualitas dari penugasan tersebut, sehingga tidak dapat merepresentasikan tentang pengalaman auditor. Hal ini merupakan salah satu kelemahan dari penelitian ini.

Kredibilitas klien memoderasi hubungan antara profesionalisme auditor pada pertimbangan tingkat materialitas. Hal ini ditunjukkan dengan nilai t-statistik $\geq 1,96$ yakni sebesar 4,209. Setelah profesionalisme auditor diinteraksikan dengan kredibilitas klien, pengaruhnya berubah menjadi bernilai positif $(0,415)$. Artinya, tingkat profesionalisme seorang auditor dapat berubah setelah memiliki kepercayaan pada klien sehingga akan berdampak pada keputusan auditor dalam memberikan pertimbangan tingkat materialitas. Dengan demikian, kredibilitas klien memperkuat hubungan antara profesionalisme auditor terhadap pertimbangan tingkat materialitas. Hubungan yang positif berarti bahwa seorang auditor profesional yang sudah memiliki kepercayaan kepada klien, maka akan dapat lebih longgar atau mudah dalam memberikan pertimbangan tingkat materialitas atau lebih akomodatif terhadap keinginan klien.

Kredibilitas klien juga memoderasi hubungan antara etika profesi dengan pertimbangan tingkat materialitas. Hal tersebut ditunjukkan oleh nilai t-statistik $\geq 1,96$ yakni 2,456 dan koefisien jalur menunjukkan angka -0,314. Setelah etika profesi diinteraksikan dengan kredibilitas klien, menjadikan pengaruh etika profesi pada pertimbangan tingkat materialitas menjadi signifikan. Hubungan diantaranya negatif artinya kredibilitas klien memoderasi secara negatif atau memperlemah hubungan antara etika profesi pada pertimbangan tingkat materialitas. Hal ini berarti bahwa ketika seorang auditor yang memegang etika profesi yang kuat serta memiliki kepercayaan kepada klien, maka akan dapat memberikan pertimbangan tingkat materialitas meskipun dalam tingkatan pertimbangan yang sangat ketat. Artinya keputusan yang diberikan auditor 
tidaklah sangat mudah begitu saja menuruti keinginan klien.

Kredibilitas klien bukanlah variabel moderating yang dapat mempengaruhi pengalaman auditor terhadap pertimbangan tingkat materialitas. Hal ini ditunjukkan oleh nilai t-statistik <1,96 yakni 1,580 dengan koefisien jalur sebesar 0,121. Hal tersebut dimungkinkan karena lamanya bekerja dan banyaknya penugasan auditor belum bisa merepresentasikan tentang pengalaman auditor meskipun auditor memiliki kepercayaan terhadap klien. Hasil penelitian ini sesuai dengan penelitian yang dilakukan oleh Budi Susetyo (2009) dimana hasil penelitian menunjukkan bahwa kredibilitas klien tidak memoderasi pengaruh pengalaman auditor terhadap pertimbangan tingkat materialitas.

\section{SIMPULAN DAN SARAN}

\section{Simpulan}

Penelitian ini memberikan kesimpulan sebagai berikut:

a. Semakin tinggi tingkat profesionalisme yang dimiliki seorang auditor, maka pertimbangan dalam memutuskan pemenuhan keinginan klien akan semakin ketat atau akan semakin tidak mudah dalam rangka memenuhi keinginan klien.

b. Etika profesi tidak mempengaruhi pertimbangan tingkat materialitas, hal ini dikarenakan etika profesi lebih cenderung ke arah perilaku seorang auditor dalam menjalankan tugasnya sebagai seorang individu, bukan terhadap pertimbangan auditor.

c. Pengalaman auditor tidak berpengaruh dalam memberikan suatu pertimbangan tentang materialitas.

d. Kredibilitas klien memperkuat hubungan antara profesionalisme auditor terhadap pertimbangan tingkat materialitas.

e. Auditor yang memegang etika profesi yang kuat serta memiliki kepercayaan kepada klien, maka akan dapat memberikan pertimbangan tingkat materialitas meskipun dalam tingkatan yang sangat ketat.

f. Kredibilitas klien tidak memoderasi pengaruh pengalaman auditor terhadap pertimbangan tingkat materialitas.

\section{Saran}

Penelitian selanjutnya hendaknya mempertimbangkan hal-hal sebagai berikut:

a. Memperluas cakupan wilayah penelitian untuk meminimalisasi bias akibat rendahnya variasi responden dan hasil penelitian dapat digunakan untuk generalisasi.

b. Menambah jumlah sampel agar tingkat keterwakilan anggota populasi semakin tinggi.

c. Menambahkan faktor-faktor lain yang dapat mempengaruhi dari variabel dependen tersebut. 
d. menyempurnakan instrumen penelitian yang digunakan.

\section{DAFTAR PUSTAKA}

Al.Haryono, Jusup. (2001). Auditing. Buku 1. Yogyakarta: Bagian penerbitan STIE YKPN.

Arleen Herawaty dan Yulius Kurnia Susanto. Pengaruh Profesionalisme, Pengetahuan Mendeteksi Kekeliruan, dan Etika Profesi Terhadap Pertimbangan Tingkat Materialitas Akuntan Publik. Jurnal Riset Akuntansi Indonesia. Vol.8, hlm 13-20.

Badudu dan Sutan. (2002). Kamus Umum

Bahasa Indonesia. Jakarta: Pustaka Sinar Harapan.

Budi Susetyo. (2009). Pengaruh Pengalaman Audit Terhadap

Pertimbangan Auditor dengan

Kredibilitas Klien sebagai variabel Moderating. Tesis. Semarang:

Universitas Diponegoro.

Dila Fadhilatun Nisa. (2010). Dampak Aturan Etika, Standar profesi, Komitmen Profesi dalam Meningkatkan profesionalisme Auditor Internal. Skripsi. Jakarta: Universitas Islam Negeri Syarif Hidayatullah.

Hastuti, T.D., S.L. Indriarto dan C. Susilowati. (2003). Hubungan antara Profesionalisme dengan PertimbanganTingkat Materialitas dalam Proses Pengauditan Laporan Keuangan.
Prosiding Simposium Nasional

Akuntansi. Oktober. hal 1206-1220.

Herawati dan Susanto. (2009). Pengaruh Profesionalisme, Pengetahuan dan Etika Profesi terhadap Pertimbangan Tingkat Materialitas Akuntan Publik. Jurnal Akuntansi dan Keuangan Vol.11 No. 1. Jogiyanto, H.M. (2004). Metode Penelitian Bisnis: Salah Kaprah dan PengalamanPengalaman. BPFE: Yogyakarta.

Mulyadi. (2002). Auditing. Buku 1, Edisi 6. Jakarta: Salemba Empat.

Sinaga, M. (2012). Analisis Pengaruh Profesionalisme Terhadap Tingkat Materialitas Dalam Proses Pengauditan Laporan Keuangan. Tesis. Semarang: Universitas Diponegoro.

Solimun. (2010). Analisis Multivariat Pemodelan Struktural metode Partial Least Square-PLS. Malang: CV. Citra Malang.

Sugiyono. (2010). Statistika Untuk

Penelitian. Bandung: Alfabeta.

Wahyudi dan Mardiyah. (2006), Profesionalisme Akuntan dan Proses Pendidikan Akuntansi di Indonesia. Jakarta: Pustaka LP3ES. 